in Australian Educational Researcher (2000), 27 (3), 59-77

(special issue of Australian Educational Researcher on Social Justice)

\title{
Social Justice and the Middle
}

Lyn Yates and Julie McLeod

University of Technology, Sydney

and

Deakin. University

Contact details (* Address for correspondence):

* Professor Lyn Yates, Faculty of Education, University of Technology, Sydney, PO Box 222, Lindfield, NSW 2070. lyn.yates@uts.edu.au ph0295145230 fax 02 95145620

Dr Julie McLeod, Faculty of Education, Deakin University, Burwood, Vic 3125. jemcleod@deakin.edu.au ph0292446298. 


\section{Social Justice and the Middle}

Do you think the school you're at makes much difference to where you end up in life or what kind of person you become?

Well it does. I think so. Because different schools attract different sorts of people, and they also I think help mould you into sort of beliefs and that sort of thing.

(male, year 12 student, 1999)

'Social justice' is not a straightforward concept; and nor is the question of what schools do in relation to it. In this article we want to elaborate a little on the first of these claims, and illustrate the second by choosing to talk about two 'middle' or 'ordinary' high schools and their apparent impact on the students in them whom we followed in a longitudinal study from 1993 when they were in grade 6 to the present year, when most have finished school.

\section{What is 'social justice'?}

Earlier this year, at the conclusion of an international conference on Education and Social Justice ${ }^{\mathrm{i}}$, David Hamilton was asked to report back to the conference what he had heard to be its key themes. After two days of papers on a range of topics and issues - educationally disadvantaged groups of various sorts; new right movements; system reorganizations that were reinforcing past inequalities; global economic impacts on national education policies - Hamilton commented: 'I've heard a lot of papers about social injustices, but not ones taking up the issue of social justice'.

As Hamilton observed, 'social justice' is a considerably more problematic concept at this present point in history than social injustice. ${ }^{i i}$ The claims of different types of social movements (feminist, postcolonial, anti-racist, disability rights) have muddied the waters about what a 'socially just' society would look like (Young 1990). 
Theorists are more sceptical and aware of the dangers of unitary utopian models and the questions and interests these might silence (Butler 1995). And, as Michael Apple (Apple 2000) has argued, there is not today a powerful and popular vision of a 'just' alternative at work in the public commonsense in the way that the vision or spectre of economic efficiency, competitiveness, individualism has taken on.

Nancy Fraser (Fraser 1997) is one who acknowledges 'the current absence of utopian vision', but sees it as a sign of expanded concerns which have not easily come together in the contemporary world:

we are witnessing an apparent shift in the political imaginary, especially in the terms in which justice is imagined. Many actors appear to be moving away from a socialist political imaginary, in which the central problem of justice is redistribution, to a "postsocialist" political imaginary, in which the central problem of justice is recognition. Some celebrate the shift "from redistribution to recognition" as if struggles for distributive justice were no longer relevant. Others bemoan the decentering of class, which they equate with the decline of egalitarian economic claims, as if struggles for racial and gender justice were "merely cultural" and not also addressed to distribution... These, I maintain, are false antitheses... ((Fraser 1997): 2-3)

Michael Pusey’s Middle Australia Project (Pusey 1998b) , (Pusey 1998a), a study of the views of 'ordinary' or 'middle’ Australians today, also provides some empirical support for the importance of expanding concerns about 'social justice' beyond a narrowly distributional concept. The study reports some increasing inequalities of income and increase in economic uncertainty that many in the middle are feeling, but also taps people's even greater concern about the changes in family and social forms and the inadequacy of public social arrangements in relation to these.

Taking up 'social justice' in relation to education raises broad questions about social relations and social advantage and disadvantage, and a need to recognize that there is not just a single scale of disadvantage. The production of immediate distributional outcomes is one part of this, but not the whole. What schools do to and for the students in those schools is also part of it, but not the whole. The values that those students acquire and take with them in relation to other individuals and social groups 
- what kind of society the schools are helping to produce - is also worthy of attention. As Sharon Gewirtz has argued, we need to be conscious of the 'relational dimension of social justice',

the nature and ordering of social relations, the formal and informal rules which govern how members of a society treat each other

(Gewirtz 1998), p.471.

Gewirtz adapts Iris Marion Young's conceptualization of social justice as relating to concerns about five different 'faces of oppression': exploitation, marginalization, powerlessness, cultural imperialism and violence (Young 1990), to set out the questions these raise for education:

How, to what extent and why do education policies support, interrupt or subvert:

1. Exploitative relationships (capitalist, patriarchal, racist, heterosexist, disablist, etc.) within and beyond educational institutions?

2. Processes of marginalization and inclusion within and beyond the education system?

3. The promotion of relationships based on recognition, respect, care and mutuality or produce powerlessness (for education workers and students)?

4. Practices of cultural imperialism? And which cultural differences should be affirmed, which should be universalized and which rejected?

5. Violent practices within and beyond the education system?

(Gewirtz 1998), p.482.

In relation to all these issues, it is of relevance to look closely at the subjectivity of students as they develop in particular school contexts, and this is what we set out to do in our qualitative, longitudinal research project.

\section{The 12 to 18 Project, subjectivity, zeitgeists and social justice}

In 1993, we began the 12 to 18 Project (Yates and McLeod 1996), to follow in some detail what happened to students who were about to enter four different secondary schools in Australia. We came to it imbued by some of the research traditions that have been important within the two different themes that Fraser identifies, and that have fed the formulations that Young and Gewirtz take up ${ }^{\text {iii }}$. In terms of the politics of distribution, we were interested in revisiting the longstanding interest in schooling's 
part in 'who gets what'; so we set up our study to include an elite school and another in a disadvantaged area, as well as two in the middle, and we set it up too to include students from different backgrounds (class, gender, ethnicity) attending the same school, and students from similar backgrounds attending different schools. In terms of the politics of recognition, we were interested in schooling's part in the construction of gendered identity and the different forms this takes - in the values that are formed about what is constituted as the norm, as right ways of thinking, about who, what and how is other. We set up the study to take the form of lengthy interviews with the same students, twice a year, over the seven years from twelve to eighteen.

By its nature, a small-scale, qualitative study is not a test of what each school produces as retention, success rates, post-school outcomes; quantitative data is necessary to check the overall picture. (Teese 2000, Collins 2000) ${ }^{\text {iv }}$ What our study assumed was relevant to understanding this bigger picture, and where its potential contribution lies, is in exploring the subjectivity of the students being shaped in the course of this process. Like Fraser then, we assume that 'distribution' and 'recognition' are not antitheses but intimately linked when it comes to studying what school does to produce fairness and unfairness, advantage and disadvantage, lesser and greater forms of social equality.

Indeed, from the beginnings of the equal opportunity work in relation to girls in the 1970s, the issue was never simply about ‘distribution' of school success (Yates 1986, Yates 1993, Yates 1996, Yates 1997, Collins 2000), but about the creation of world views and identities that reduced women's power and opportunities in later life. And, since the 1970s, the most creative work on how 'class' differences are reproduced through education pays a lot of attention to issues of identity and subjectivity and the reception these are given in school (for example, Young 1971, Bourdieu 1998, Willis 1977, Walkerdine, Lucey and Melody forthcoming, Teese 2000). Moreover, the focus on identity and subjectivity has a particular imperative today:

Identity resources are increasingly critical to social actors in a society of risk and uncertainty as opposed to a society of reproduction and roles. 
(McDonald 1999), p.6)

And what the work around gender, 'multiculturalism', 'inclusive education' brought to the fore, was that issues of related to social justice and schooling are not confined to what that school does for an individual in terms of 'equal opportunity'. The work of schools is also part of the broader creation of a social and cultural zeitgeist about who matters and what matters and what counts as fair and unfair treatment of individuals and groups. These impact on citizenship, on labour regulation, on discrimination, on interpersonal experiences; and they also become taken up in each individual's sense of themselves, their capacity, their significance, their potency in the world.

One way then of talking about issues of social justice in relation to 'ordinary' high schools is to think of this in terms of questions about, 'what does this school open up or shut down for students?', 'what does the school make possible for its students beyond the immediate post-school entry?' and 'what patterns of social orientations and values beyond school are being produced by schooling and by this particular school?' And, overall, 'what is this school producing in relation to the various senses of exploitation, marginalization, powerlessness, etc, discussed by Young and by Gewirtz?' In other words, as we argue above, the issues of social justice relate to what happens to individuals and groups in that school and also to what is being developed through them as orientations to the social whole, the 'formal and informal rules which govern how members of a society treat each other'.

In terms of this argument, the discussion of 'social justice' and education should not be restricted to the study of 'disadvantaged' and 'ruling class' students or schools: what every school does (and what all schools together do) warrants scrutiny. In this article we have decided to focus on the two 'middle' schools in our study, rather than the two that were more obviously elite and disadvantaged ${ }^{\mathrm{v}}$. Schools like these, ordinary high schools that are neither elite nor extremely disadvantaged, form the great bulk of schools in Australia and yet they have received relatively little attention 
from researchers specifically interested in broad patterns of social inequalities and social relations. (Watson 1993, Yates forthcoming).

The 12 to 18 Project is now in its final stage. This year (2000), the students are 18, and all except a few whose study has been interrupted have left their schools. In familiar ways, students from richer backgrounds, students with plenty of 'cultural capital', got high results, and are on track to reproducing their initial advantages; students from poorer backgrounds, in poorer neighbourhoods, are more likely to now be not in tertiary studies, and to be unemployed and facing future economic uncertainty (though in both cases, there are exceptions; and a more complex picture could be given). (Yates 1999, Yates 2000a, Yates forthcoming, McLeod forthcominga, McLeod forthcoming-b). But here we want to talk about the two schools in 'the middle', and what happened to the students who went to them. ${ }^{\text {vi }}$

\section{Two ordinary high schools and questions of 'social justice'}

The two 'middle schools' of our study which are the focus of this article both drew students from a range of family backgrounds - from poor and unemployed to small business people, and parents working in professional occupations. In other words, these were high schools not so typed as 'disadvantaged' that no 'middle class' children entered them; they were schools with some positive reputation, and where some students have gone on both in the past and in the current study to tertiary studies; but they are not selective schools or confined to a narrowly middle-class population. One of the schools ('Suburban High') is located in a largely middle-class suburb of Melbourne, the other ('Provincial High') in a large provincial city. The questions we want to raise here are, what is being done in these schools, schools at least as common in Australia than the extremes which attract so much more research, that is contributing to social justice or social injustice?

Given the constraints of space in this article, we will not focus here on intra-school issues, of what each school does to distribute success and failure, or to expand or contract self-understandings of their own capacities among the students of different backgrounds who attend. Rather we want to focus on the way, overall, each school 
seems to be producing a different form of outcomes, a different form of seeing oneself and one's place in the world, a different form of thinking about other social groups.

We want to begin, then, with the end point of the study. All of the students began secondary school in 1994. By this year, 2000, at Suburban High, of the seven students who were our initial focus at this school:

- one left school in year 10 to take up an apprenticeship, but has dropped out before completing this

- one had hoped to get into a university course in an information technology area, but got a disappointing VCE result, and is doing a TAFE one-year course in a similar area

- two are still at school because they dropped some of their studies last year (in one case, there were medical problems involved)

- one took up an overseas exchange in year 11, and has not, as he had originally planned, returned to finish his schooling (though he has returned)

- three began university courses, and of these

o one had dropped out by May when we did the interview,

o one was considering dropping out,

0 the other was continuing and had found a subject area she enjoyed (Women's Studies).

The impression we had overall of these somewhat diverse students was that they did not feel highly driven to get on the career track, and were unlikely to express a strong commitment to a particular job or field of study. Many conveyed an 'aimlessness', a sense of uncertainty about their immediate and distant futures. For some students this uncertainty caused some concern, for others it was understood as part of growing up, of 'finding yourself', but most did not convey a strong sense of work-related ambition to 'get on in the world' (with the partial exception of two boys from different ethnic backgrounds).

At our second school, Provincial High, all except one of the students we began with now seem firmly on a vocational track. Three of the six students we studied are now 
at university (all doing directly vocational courses); one is doing a TAFE course in her chosen field (hotel management); one was accepted at university but is working prior to applying to join the police; and one left school as soon as he was old enough (year 10), and when last we made contact was doing casual work in a supermarket. The impression we had of these students from the interviews this year (we were not able to interview the student who had left earlier) is that they all had clear plans about what they were doing and where they were going, and indeed in most cases were not only taking a vocational course or path but had further plans about what they were going to do next, and were taking steps to make that happen (for example, going to the gym regularly, to pass the police fitness test; applying for a RAAF scholarship with plans of completing nursing within the airforce; finding out options for continuing beyond the current degree to do a graduate degree in medicine).

Students from the two schools also volunteered different reflections and memories of their school experience. Those who had attended Suburban High spoke very warmly of teachers and the caring they had received, of the fact that it gave them second chances. Those who had been to Suburban High also spoke of the student mix and culture at the school both positively (appreciated its diversity) and, in some cases, as something that made it hard to excel.

At Provincial High, when we asked the same questions, "Do you think this was a good school?" and "Do you think it was the right school for you?”, the ex-students of the school were more likely to hesitate before replying. Their story also was positive about their school being a 'good' one; but they were more likely to offer some criticisms about the teachers; and were much less enthusiastic about their teachers than the students at Suburban High. They thought their school had good facilities, but many made comparisons with students at private schools, and said they did not get as much individual attention as those students.

In both cases, the themes in these final interview comments reflected a picture of the two schools that had been consistent through the previous six years of interviews. ${ }^{\text {vii }}$ In the remainder of this paper, we want to draw out some aspects of what seems to be 
happening here in terms of the two schools' roles in and relationship to social hierarchy; and in terms of maintaining a focus on both distribution (who gets what) and recognition (how individuals and groups are advantaged or harmed) in terms of what these schools are doing.

First, let us consider social hierarchy and 'distinction', especially as theorized by Pierre Bourdieu (Bourdieu and Passeron 1977, Bourdieu 1984, Bourdieu 1998) a theorist whose work is now being quite widely called on in education. (Ball 1998, McDonald 1999, Teese 2000). In very simple summary, Bourdieu's argument is that schooling contributes to social inequality by giving success to those groups who possess existing cultural advantage, and by appearing to be not doing that but rather rewarding individual intelligence and effort. One of the ways this occurs is by unstated 'distinctions' whereby those whose background is not already one of familiarity with and success in the education system are made conscious of their otherness, the closer they get to the levels and markers of academic success. More commonly, 'habitus', the acquired dispositions related to particular family social locations, ensures that groups learn to value the things that lead to the reproduction of their situation - just as, in his classic study of working-class lads, Willis (1977) found that bright working-class boys valued behaviour marked by disdain for academic schooling.

Bourdieu's theories have been extremely useful for understanding some elements of how students from different backgrounds (habitus) see and are seen by their schools. But it is tempting in terms of this work to slide into a reproductive model in which habitus of family and school are conflated, and in which particular forms in which different schools may operate are glossed over. This is where some comparison of Suburban High and Provincial High is of interest. Accepting broadly some of the arguments of Bourdieu and Richard Teese about the big picture and class-based cultural advantages and disadvantages of different students in Australia, we have in these two schools, with some broadly similar (though certainly not identical) intake, two different ways of relating to the 'cultural arbitrary', two different representations of what is valued. At one school, relativities of positioning in the economic and status 
social hierarchy are emphasized and taken as an explicit agenda for both school and individual; at the other, it is a submerged background, not part of the school's strong agenda. One would expect these different modes might create some difference both in terms of the fate of the individual students, and in terms of the broader values they produce.

Provincial High, is a school that takes very seriously many of the things that Bourdieu sees as important markers of social hierarchy and power, and as keys to what might be called social injustice, or the reproduction of inequality. (The quote at the beginning of this article is from a student at this school.) The school overtly values winning and academic success and has the reputation of being an academic and sporting school; but it is attuned also to the types of distinctions that mark out social hierarchies and the claims to be among the elite. When we ask students at this school what they think of the school, or how the school compares with other schools, they talk at great length (compared with students from the other three schools in our study) about the comparisons involved. They constantly refer to material facilities, behaviour, reputation with the public, and, above all, participation in a sporting activity associated with elite schools as the things that mark this as a 'good' school. Making a comparison to another high school in the same city, one student says

Yeah, they have a higher VCE, but they don't have like a too good a reputation. 'Cos all fights and stuff break out over there, and it's a dirty school. That's what a lot of people say and that. So I think we have a better reputation than a lot of other schools.

(year 7 girl, 1994)

In terms of 'distributive' social justice', this school produces respectable results though not as good as its reputation might suggest. On the 'valued added' scale of VCE results ${ }^{\text {viii }}$ now published annually, this school hovers around 100, which is interpreted to mean that the school produces results that neither add nor detract much in terms of advantages to the (relative, school-assessed) 'intelligence' of the students who enter. (Interestingly, Suburban High produces a similar pattern on this measure though the two schools have different reputations in their respective communities, 
with Provincial High positioned very much as a 'good' successful, academic school; and Suburban high positioned as somewhat alternative, and not highly academic.)

The history and situation of Provincial High was one where the interest in distinction, and in the way public (state) schools might measure up to elites, was prominent. Students in our study already could speak about these issues when we first interviewed them in grade 6, prior to coming to the school. As they went on, the interest in the comparisons and social distinctions remained high. The students both explicitly and implicitly reflected this school's values in their ongoing concerns about success and about artefacts of success; their belief in the importance of public appearances, reputation and achievements as being more important than some of the processes along the way. For example, this seemed to be a school where bullying of boys in the junior years was particularly rife; and where students did not feel that such issues were likely to be seen by or adequately addressed by, their teachers. At the end of school, compared with the other schools in our study, we heard few warm comments about the teachers and about their time at school. This did not seem to be an environment which was sensitive to racism, or concerned in an explicit way with 'inclusiveness'.

In the course of our study, one of the six students left school as soon as he reached the legal age - a likelihood that had been predicted by the Pupil Welfare Co-ordinator three years earlier when we first interviewed him in year 7 ! The boy was following a pattern of his older brothers, and the school seemed simply to accept that this would happen. But the other five people in our study, though they come from different types of family backgrounds in terms of SES, ethnicity and family values, are doing a range of courses and work now, and all have strong and strategic plans for where they intend to go over the next five years.

To summarize, in terms of what the school produced as outcomes, and in terms of how students talked, Provincial High generates a sense of a world in which individual effort and hard work bring rewards, and constant effort and vigilance is needed to keep up with those at the top of the social hierarchy, who are always an explicit point 
of comparison. The outcomes for individuals are positive in terms of the types of things parents and policy-makers worry about: attachment to career routes, taking action, being strategic, being hard-working, being energetic. Students who make it through to year 12 here acquire a strong sense of their own responsibility and efficacy to take action to shape their own future. At the same time the students are accepting a rat-race in which they compete at a disadvantage. Listening to their experiences over the six years of secondary school makes clear the amount of disciplinary work that goes into being seen as 'as good as' the private schools - and of course 'as good as' itself carries the message that you are not one of them. These students are also being nurtured into individualist ways of thinking that puts the responsibility for one's fate on the individual, and that carries with it relatively little empathy for victims of bullying or racism.

Where Provincial High was a school whose central motifs were concerned with distinction, hard work, and winning; Suburban High, was a school with some pride in a tradition of being a bit alternative, or being inclusive, of looking after its students. When we started our study, enrolments had been dropping (a sign of the increased competitiveness and focus on outcomes that recent times have generated), but although the school took on some of the markers of new discipline (for example introducing a uniform) and was successful in reversing the dropping enrolments, the ethos of the teachers, and the school publicity to itself in its newsletter and noticeboards maintained a quite different set of values than at Provincial High.

From students' comments over the years of our study, we had a sense that this was a school that paid a lot of personal attention to students, tried to help them and give them second chances, and where there was genuinely less racism than at other schools. (Of course all the schools in this study formally declared racism and sexism to be unacceptable; but in Suburban High it actually carried through into students' broader answers about incidents and social issues related to difference and racism in and out of school; and in their own judgements about what they thought the school valued, and what they thought the strengths of the school were.) Students spoke very warmly of teachers - both in general and in relation to particular teachers, and 
reported one of the strengths of the teaching as being its ongoing commitment to 'giving you another chance'. For the individual students, the result seemed to be that they felt nurtured, treated therapeutically, but not highly pushed. Though drug-taking was present and talked about by students at all of the schools in our study, at this school it seemed more normalized. Students not only found it easy to get involved in drug-taking, but found it easy to talk about this, and difficult to give up, even when they were wanting to do so in the run-up to the final year 12 certificate.

When students at Suburban High made comparisons with other schools, they did not focus on social hierarchy so much as the style and the culture of this school. As individuals, students felt less pressure, and one consequence seemed to be that in this immediate post-school year many have not advanced along the educational pathways to the extent that they might have at another school.

Do you think the school was a good one, or do you think it was the right one for you, the school?

Um, I think I might have done better if I was at maybe one of the private school's dad wanted me to go to, but I was happier there, like I think it was a good school, yeah.

(18 year old female, May 2000)

This young woman goes on to say that a private school would have been 'more disciplined' and 'stricter', but that at Suburban High she liked her friends, and she liked the teachers, and by comparison, when she went on to university 'it was so daunting there was just so many people and you didn't know anyone' (and she dropped out of that environment within two months of starting there).

Provincial High, at least as reported by the students, was not highly attuned to differences in socio-cultural identity and background, but was highly sensitive to the public circulation and markers of social distinction, and was highly directed to an individualist view of progress and possibility. Suburban High, at least as reported by students over seven years of interviews, was highly sensitive to individual and group difference, and nurtured a sense of good relationships ('recognition') rather than 
having an impact on distributional inequalities (indeed, students here were inclined to resign themselves in advance to not getting where they would like).

So the schools seemed to have some impact on individual and short-term identities and achievements; what were they producing in terms of the longer term, and the broader politics of a just or unjust society? Here, we want to consider the things discussed by students at each school in relation to some general questions we asked them all in an interview when they were in year 10: Do you think long term unemployment is an important issue in Australia today? What do you think are the causes of unemployment? Do you think long terms unemployment will have any impact on your life?

At Provincial High, here is a very characteristic way of answering these questions:

I think everyone should be able to get a job, because then they get responsible and they have to, everyone has to learn how to be responsible, how to be reliable, how to do things, because that's just the way society is, that's the way life is, that's the way everything goes. And the world runs like that. So for people that aren't employed and don't want to be or are finding it hard to get a job, I would try to encourage them as much as I could because you've got to, it's important and it's good for you, you'll benefit from it?

What do you think causes long term unemployment?

Um, sometimes people’s attitudes...

And do you think it's likely to have any impact on your life?

No, I've got my goals. I'm going to go for them. I'll do the best I can and hopefully with my qualifications I'll get a good job at least. If I'm not getting the one I want, at least I'll get a good job. That's you know, that's fine.

(year 10 female, 1997)

This student, and the others from this school, have accepted the message that one's outcome in life is a result of schooling and hard work. But they are also conscious of the relevance of social distinction (how one dresses, for example); and of the limitations of location and job availability. There is considerable stress on individual responsibility, an awareness of lurking possibilities of a difficult and competitive 
environment, and that they will have to work hard and be alert if they are not to fall prey to this. These are some of the comments they made:

I see it as a huge issue because my brother has finished school and I can see how hard it's going to be to get a job

probably one of the biggest things is dropping out of a school and not having an education to get a job over other people who have stayed in school.

Some of them I don't think want to go out and work.

a lot of people that have been out of work for a while, and that sort of thing just leads to alcohol and drug use in the, ah, how would you put it, lesser richer populations of [this city].

What do you think are the causes of unemployment?

Probably the way they think about themselves, or the way they dress, or, um, yeah, the way they think because of where they live. They don't have much self-esteem. [...] They sort of don't think they can get a job. If you think like that you won't get a job.

(year 10 interviews, 1997)

That was Provincial High, the young people whose views at the end of school, were that it had been a good school, had been measuring up in a competitive environment, but did not feel particularly warm about it. For the individual student, it had generated a striving to work hard, to keep in there as much as possible, a drive to selfimprovement but a willingness to be realistic about aspirations. In terms of orientations to a more long-term social whole, it was producing a sense that the unemployed deserve little sympathy, that outcomes are the result of individual application and effort. The existence of social distinction might be recognized, but there was little railing against unfair distribution of starting point advantages and power; wistful envy rather than resentment framed their attitudes towards the advantages of private schools.

When we asked students at Suburban High, a similar set of questions about unemployment at the same point in their schooling, they gave a rather different set of perspectives on society, jobs and individual effort relation to this. Where students at 
Provincial High had responded to these questions as an invitation to repeat the message about the importance of finishing school, of working hard, these students at Suburban High responded to the question with a more distanced reflection on the shape of social change, and respond in ways that is much more in tune with a 'left' view of the world. Social change has happened; it creates problems; employers close down jobs.

Do you think that long term unemployment is a serious issue in Australia today?

I guess so.

What do you think causes unemployment?

Well, there's not enough jobs, and then people get discouraged because they can't get a job, so they give up. And some people are just lazy.

Do you think that long term unemployment will have any impact on your life?

Um, probably, I don’t know really.

(female, year 10, 1997)

And what do you think are the causes of unemployment?

Things being closed. Not enough, like jobs within a job, like just say in a factory there's not like, there could be more people working. Like they're just making excuses $[\ldots]$

And do you think long term unemployment will have any impact on your life?

Yep, because it might mean that I won't get a job. And if I don't get a job, well then I can't, like if I leave home, well once it's time to leave home, because I want to leave home like around 18,19,because that's after I finish school. Um, and if like I can't find a job, well then I'm going to be in a bit of trouble. I mean like my parents are putting money in and stuff into my over 18 account, and like I'll have a bit then, but it won't last me long. Like when you think about when you've got your own house and you have to pay all the bills and stuff, it won't last long.

(female, year 10, 1997)

What do you think causes unemployment?

Um, probably companies not offering jobs.

Do you think that unemployment will have any impact on your own life? 
Oh, hopefully not. I hope it doesn't affect me at all. But I don't know what the future holds.

(male, year 10, 1997)

What do you think are the causes of it?

Probably people not being qualified and you know you need, more and more you need qualifications to get jobs, so people, say, are getting a bit older and are unqualified, and it's much harder to get a job because so many people are looking for them.

And do you think unemployment will have any impact on your own life?

Um, if I decide to start, go on the art side of things. I would probably be self employed if I did that. But, I mean, I could have a problem with money coming in, but I wouldn't be unemployed, I'd never be unemployed if I was self employed. But if I was, possibly if I was trying to get, oh, I hope not, I don't think so, but could.

(male, year 10, 1997)

Even the final student quoted here, the one who associates unemployment to some extent with lack of qualifications, is referring to a historical pattern that has caught out some older people, not a message to himself (or others) to work harder now.

Students at Suburban High do not take unemployment as a personal reflection on the unemployed, but just as something that happens for reasons outside their control. In relative terms, this school was doing well on 'the politics of recognition'; but distinctly less well on the distributive side (at least at this immediate post-school stage). The sense of the students sitting back, not sure what will happen, not showing signs of wanting to take very active steps to make things happen, which is evident in the year 10 interviews just quoted, is sustained and still evident in our most recent interviews when most have finished school. In the recent interviews, for example, one student spoke of wanting to continue his studies, but just could not get himself organized to do this; another was vaguely dissatisfied with the university course she began, and found travelling there by public transport too much trouble - and had dropped out within two months of beginning the degree.

\section{Final reflections}


Schools distribute success and failure; they also teach people things; and they impact on individuals and groups in both the short term and the long term. With these students from two 'middle' high schools in our study, we see some 'school effect' on where the students from each seem to be oriented by this first post-school year, some different ways of seeing what matters and of thinking about the relations between individuals, group characteristics and the social whole. In each case issues of 'distribution' and 'recognition' are intertwined; in each case, the directions set in train have some consequences both for the individuals themselves, and for broader development of Australia's polity, economy, and relations between its citizens.

In the case of Provincial High, in the short-term at least, the school is not producing an overly sympathetic orientation to most of the issues for social justice that Gewirtz set out. The students appear to be not highly sensitive to, nor interested in, issues of group marginalization and inclusion, of recognition and respect, of violence, that have marked the new social movements around gender, race, culture. But they are aware of some of the class-based forms of recognition and the stress by this school on how one's individual future might be advanced, the sense of self-efficacy that the school also generates, contributes to greater individual opportunity for these students than they might otherwise have had. Their future sense of themselves as capable and as responsible for their own outcomes is enabling, both individually and in terms of social patterns ${ }^{\text {ix }}$, but it also feeds how these young people see and relate to others, including some lack of sympathy for those who are disadvantaged or targets of bullying and racism. At Suburban High, students are more successfully schooled in a broad range of 'social justice' concerns, and, in our most recent interviews, are carrying their sensitivities and willingness to speak out about racism and sexism into their post-school social relations. But, at least in the immediate post-school phase, they appear to be placed in a more uncertain relationship to the labour market.

Of course this has been an over-simplified picture. Our intention here was not to finely account for the processes which fed the views we reported here, nor to talk about some differences between students from different backgrounds or gender in each school. Rather we wanted to put on the agenda the issue of that big bulk of 
Australian students and schools that are roughly in 'the middle'; and to raise questions about social justice that go beyond the simple accounting of whether success and retention rates are proportional to a group's representation in the school population.

\section{Acknowledgement}

The 12 to 18 Project has been supported by funding from the Australia Research Council and with additional support from University of Technology, Sydney; Deakin University and La Trobe University. The preparation of this paper has been assisted by the work of the Project Officer on the project, Dr Michelle Arrow (UTS).

\section{References}

Apple, Michael (2000) in New Directions in Educational Research: Education, Teacher Education and Social Justice. Umea.

Ball, Stephen (1998) It's becoming a habitus: identities, youth transitions and socioeconomic change. Paper presented at British Educational Research Association Conference. Belfast.

Bourdieu, Pierre (1984) Distinction: a social critique of the judgement of taste, Routledge, London.

Bourdieu, Pierre (1998) The State Nobility, Polity Press, Cambridge.

Bourdieu, Pierre. and Passeron, J-C. (1977) Reproduction in Education, Society and Culture, Sage, London.

Butler, Judith (1995) Contingent foundations, in Seyla Benahbib, Butler, Judith, Cornell, Drucilla and Fraser, Nancy ed, Feminist Contentions, Routledge, New York, pp.

Collins, Cherry, Kenway, Jane \& McLeod, Julie (2000) Factors influencing the educational performance of males and females in school and their initial 
destinations after leaving school, Department of Education, Training and Youth Affairs, Canberra.

Fraser, Nancy (1997) Justice Interruptus, Routledge, New York.

Gewirtz, Sharon (1998) Conceptualizing social justice in education: mapping the territory, Journal of Education Policy vol.13, no.4, pp.469-484.

McDonald, Kevin (1999) Struggles for Subjectivity: identity, action and youth experience, Cambridge University Press, Cambridge.

McLeod, Julie (forthcoming-a) Metaphors of the self: searching for young people's identity through inteviews, in Julie McLeod \& Karen Malone ed, Researching Youth,Clearinghouse of Youth Studies.

McLeod, Julie (forthcoming-b) Schooling and subjectivity in a longitudinal study of secondary students, British Journal of Sociology of Education .

McLeod, Julie, and Lyn Yates (1997) Can we find out about girls and boys today, or must we just settle for talking about ourselves. Dilemmas of a feminist, qualitative longitudinal research project, Australian Education Researcher vol.24, no.3, pp.23 - 42.

Pusey, Michael (1998a) The impact of economic restructuring on women and families: preliminary findings from the Middle Australia Project., Australia Quarterly , no.July-August, pp.18-27.

Pusey, Michael. (1998b) Incomes, standards of living and quality of life: preliminary findings from the middle Australia project, in Richard. Eckersley ed, Measuring Progress: Is Life Getting Better?, CSIRO Publishing, Collingwood, pp.183-197.

Teese, Richard (2000) Academic Success and Social Power: examinations and inequality, Melbourne University Press, Carlton South.

Walkerdine, Valerie, Helen Lucey, and June Melody (forthcoming) Growing Up Girl: psychosocial explorations of gender and class.

Watson, I (1993) Education, class \& culture: the Birmingham ethnographic tradition \& the problem of the new middle class, British Journal of Sociology of Education vol.14, no.2, pp.179 - 197.

Willis, P (1977) Learning to Labour, Saxon House, Aldershot. 
Yates, Lyn (1986) Theorizing inequality today, British Journal of Sociology of Education vol.7, no.2, pp.119-134.

Yates, Lyn (1993) The Education of Girls: policy, research and the question of gender, Australian Council for Educational Research, Melbourne.

Yates, Lyn (1997) Gender equity and the boys debate: What sort of challenge is it?, British Journal of Sociology of Education vol.18, no.3, pp.337 - 347.

Yates, Lyn (1999) How should we tell stories about gender and class in schooling today?, in A-K Broch-Due \& A. Nilsen G.E.Birkelund ed, Ansvar og Protest: Kjonn, klasse og utdanning i senmoderniteten,University of Bergn Press, Bergen.

Yates, Lyn (2000a) In this brave new world... Competitive schools and postmodern research: how should we tell stories about class?, Tidskrift for lararutbildning och forskning (Journal of Research in Teacher Education Sweden) vol.1, , pp.49-67.

Yates, Lyn (2000b) Subjectivity, social change and the reform problematic. Paper presented at the New Directions in Educational Research: Education, Teacher Education and Social Justice conference. Umea, Sweden.

Yates, Lyn (forthcoming) Representing 'class' in qualitative research, in Julie McLeod and Karen Malone ed, Researching Youth, Youth Clearinghouse.

Yates, L, and J McLeod (1996) "And how would you describe yourself?" Researchers and researched in the first stages of a qualitative, longitudinal research project, Australian Journal of Education vol.40, no.1, pp.88 - 103.

Yates, Lyn \& Leder, Gilah C. (1996) Student Pathways: a review and overview of national databases on gender equity, ACT Dept of Education \& Training, Canberra.

Young, Iris Marion (1990) Justice and the Politics of Difference, Princeton University Press, Princeton.

Young, Michael, F. D. (1971) Knowledge and Control: new directions for the sociology of education, MacMillan, London.

Notes. 
${ }^{\mathrm{i}}$ Conference on New Directions in Educational Research: Education, Teacher Education and Social Justice held at Umea University, June 2000. Papers from the conference will be published in a forthcoming special issue of the International Journal of Inclusive Education.

${ }^{\text {ii }}$ At this conference, Yates expressed reservations about the use of the term 'social justice' as a banner for the type of discussions we wanted to have (Yates, 2000b). She argued that this phrase seems to call up an agreed and set form of rules against which breaches can be measured; and also begs the question of who set the rules and who comprise the judiciary. She preferred to frame her discussion around concepts of fairness, of power and inequalities, of structured advantage and disadvantage, and to assume that movements and claims around these will be ongoing.

iii Gewirtz discusses some points of difference between Fraser and Young, and makes some critique of Fraser's distinction. We do not agree with all of the interpretations of Fraser that are made in this article, but our point in this present article is to elaborate something of the range of issues that are relevant to the discussion of 'social justice' and education, a point on which the three writers agree. ${ }^{\text {iv }}$ However our selected group of students and their varied outcomes did broadly reflect the pattern shown in the broader figures for their schools.

${ }^{\mathrm{v}}$ Some discussion of the two other schools in the study can be found in (Yates 2000a) and (Yates forthcoming).

vi Our arguments about a case for giving attention to what happens in 'the middle' are not intended to imply that all disadvantages and inequalities and discriminations are equal or deserve equal priority in a situation of limited resources. In submissions to the recent inquiries about boys and schooling for our respective universities, we have both argued for the need to direct government resources to the groups who are most clearly losing out from school: poor children, Aboriginal students and in these cases too we would argue, like Fraser, that issues of 'recognition' and issues of 'distribution' are not antitheses but intimately connected.

${ }^{v i i}$ Our study is an interpretive account built on seven years of twice yearly interviews with each student - over 300 interviews in all. Explanation and justification of our methods is given in earlier writing on this project: (Yates and McLeod 1996, McLeod and Yates 1997).

viii Produced by Tim Brown of Melbourne University. This concept and measure glosses over many dubious assumptions about what is measured in the 'general achievement test' that serves as the intelligence measure.

${ }^{\text {ix }}$ In the context of Victoria as a state where those who 'make it' to positions of power and influence overwhelmingly are products of privileged backgrounds and of private schools, this school is one which has produced a number of prominent people and contributed in some small way to altering the composition and experiences of social elites. 


\section{University Library}

\section{- M M N E R VA A gateway to Melbourne's research publications}

Minerva Access is the Institutional Repository of The University of Melbourne

Author/s:

Yates, Lyn;MCLEOD, JULIE

Title:

Social justice and the middle

Date:

2000

Citation:

Yates, L. \& McLeod, J. (2000). Social justice and the middle. Australian Educational Researcher, 27(3), 59-77.

Publication Status:

Published

Persistent Link:

http://hdl.handle.net/11343/34732 